\title{
Prediction of Uniaxial Compressive Strength and Modulus of Elasticity in Calcareous Mudstones Using Neural Networks, Fuzzy Systems, and Regression Analysis
}

\author{
Naser Mahdiabadi', Gholamreza Khanlari1* \\ ${ }^{1}$ Engineering Geology, Department of Geology, Faculty of Sciences, Bu-Ali Sina University \\ Mahdieh Ave., 65178-38695 Hamedan, Iran. \\ *Corresponding author, e-mail: khanlari_reza@yahoo.com
}

Received: 25 August 2018, Accepted: 27 October 2018, Published online: 14 November 2018

\begin{abstract}
The uniaxial compressive strength (UCS) and modulus of elasticity (E) are two important rock geomechanical parameters that are widely used in rock engineering projects such as tunnels, dams, and rock slope stability. Since the acquisition of high-quality core samples is not always possible, researchers often indirectly estimate these parameters. In the present study, prediction of UCS and E was investigated in calcareous mudstones of Aghajari Formation using multiple linear regression (MLR), multiple nonlinear regression (MNLR), artificial neural networks (ANN), and adaptive neuro-fuzzy inference system (ANFIS). For this purpose, 80 samples from calcareous mudstones were subjected to the point loading, block punch, and cylinder punch tests. The performance of developed models was assessed based on determination coefficients $\left(R^{2}\right)$, mean absolute percentage error (MAPE), and variance accounted for (VAF) indices. The comparison of the obtained results revealed that, among the studied methods, ANFIS is the most suitable one for predicting UCS and E. Moreover, the results showed that ANN and MLNR respectively predict UCS and E better than MLR and a meaningful relationship between the observed and estimated UCS values in all regressions.
\end{abstract}

Keywords

uniaxial compressive strength, modulus of elasticity, ANFIS, ANNs, MLR, MNLR

\section{Introduction}

The Uniaxial compressive strength (UCS) and modulus of elasticity (E) of rocks are two basic and important geotechnical parameters for engineering applications such as a tunnel, dam design, rock blasting, slope stability, foundation engineering, and underground excavation. The direct way for determination of UCS and E is to test the specimens in the laboratory according to the ISRM and the ASTM suggested methods. To determine these parameters accurately in the laboratory, the high-quality core samples are needed. However, preparing high-quality cores, particularly from weak, densely fractured, thinly bedded, and foliated rocks is a difficult task. Uniaxial compressive strength (UCS) and modulus of elasticity (E) are among the important parameters used in designing rock structures, which are obtained through the tests on intact rocks in the laboratory [45]. Considering the mentioned difficulty involved in the preparation of high-quality cores from some soft rocks such as marl, claystone, mudstone, siltstone, slate, and thin layer rocks, many researchers have tried to estimate indirectly the uniaxial compressive strength of the rocks using the results of other experiments as well as empirical and mathematical relations. One of the newest indirect methods for estimating uniaxial compressive strength is punch-stone test results. In this research, we determine physical and mechanical parameters of calcareous mudstones of Aghajari Formation located on the Bazideraz anticline. After analyzing the obtained results, the relations of each parameter with other parameters were investigated. Eventually, the optimum balance between the mechanical indices such as point load index, block punch index, and cylinder punch index was obtained for predicting uniaxial compressive strength (UCS) and elastic coefficient (E) values using the adaptive neuro-fuzzy inference system (ANFIS).

Several researchers have used various index tests such as point load index, Schmidt hammer, P-wave velocity, porosity, density, and tensile strength in order to estimate UCS in rocks. To date, point load test have yielded the best estimation and prediction of UCS index compared 
to other tests (Sonmez et al. [35]; Diamantis et al. [12]; Yilmaz and Yuksek [44]; Basu and Kamran [10]; Heidari et al. [17]; Kohno and Maeda[23]; and Wong Li and Diyuan [42]; Khanlari and Abdi-lor [26]). Furthermore, block punch and cylinder punch tests have been used for predicting uniaxial compressive strength of different types of rocks (Van der Schrier [41]; Ulusay and Gokceoglu [39]; Gokceoglu and Aksoy [14]; Ulusay et al. [40]; Sonmez et al. [34-35]; Sonmez and Tunusluoglu [36]; Aksoy [3]; Aksoy et al. [4-5]; Karakul et al. [22]; Jafari et al. [19]; Mishra and Basu [32]; Khanlari et al. [24-26]; Abatan et al. [1]; Khanlari and Naseri [27]; Heidari et al. [18]). More recently, a wide variety of statistical methods have been utilized for developing a proper correlation between UCS index and other engineering properties of rocks, among which different statistics analysis models, multiple regression analysis, ANN model, fuzzy models, and ANFIS models have received a greater attention (Alvarez and Babuska [6]; Sonmez et al. [34]; Yilmaz and Yuksek [44]; Kahraman et al. [21]; Heidari et al. [16-17]; Manouchehrian et al. [29]; Mishra and Basu [32]; TorabiKaveh et al. [38]; Armaghani et al. [2]; Jalali [20]).
In the present study, ANFIS and ANN models were prepared for the prediction of UCS and E of different calcareous mudstones and validated using multiple linear and nonlinear regression analyses.

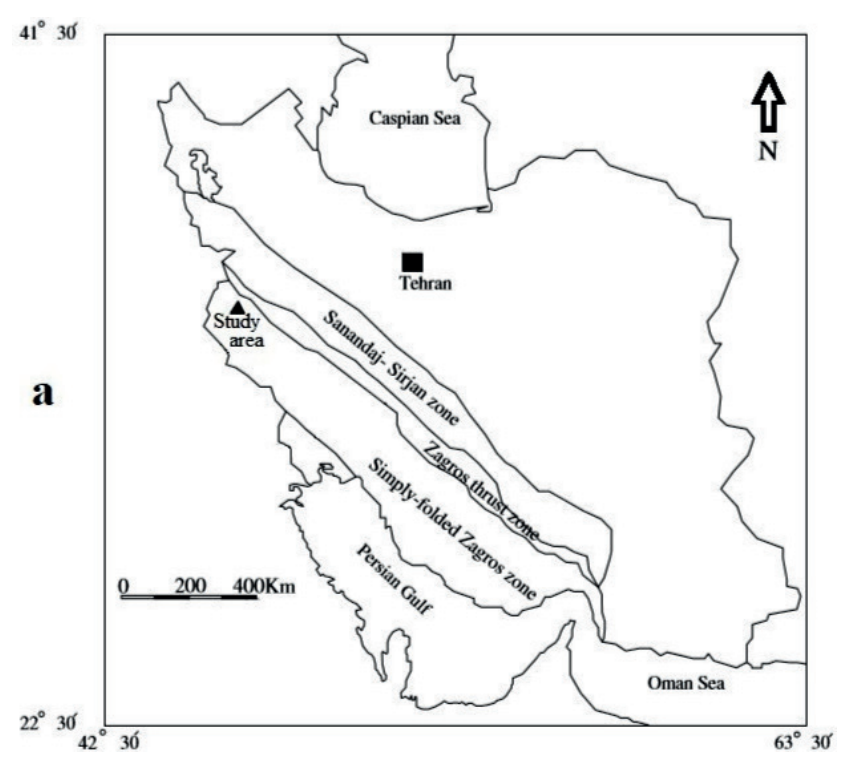

Fig. 1 a) Location of the study and area
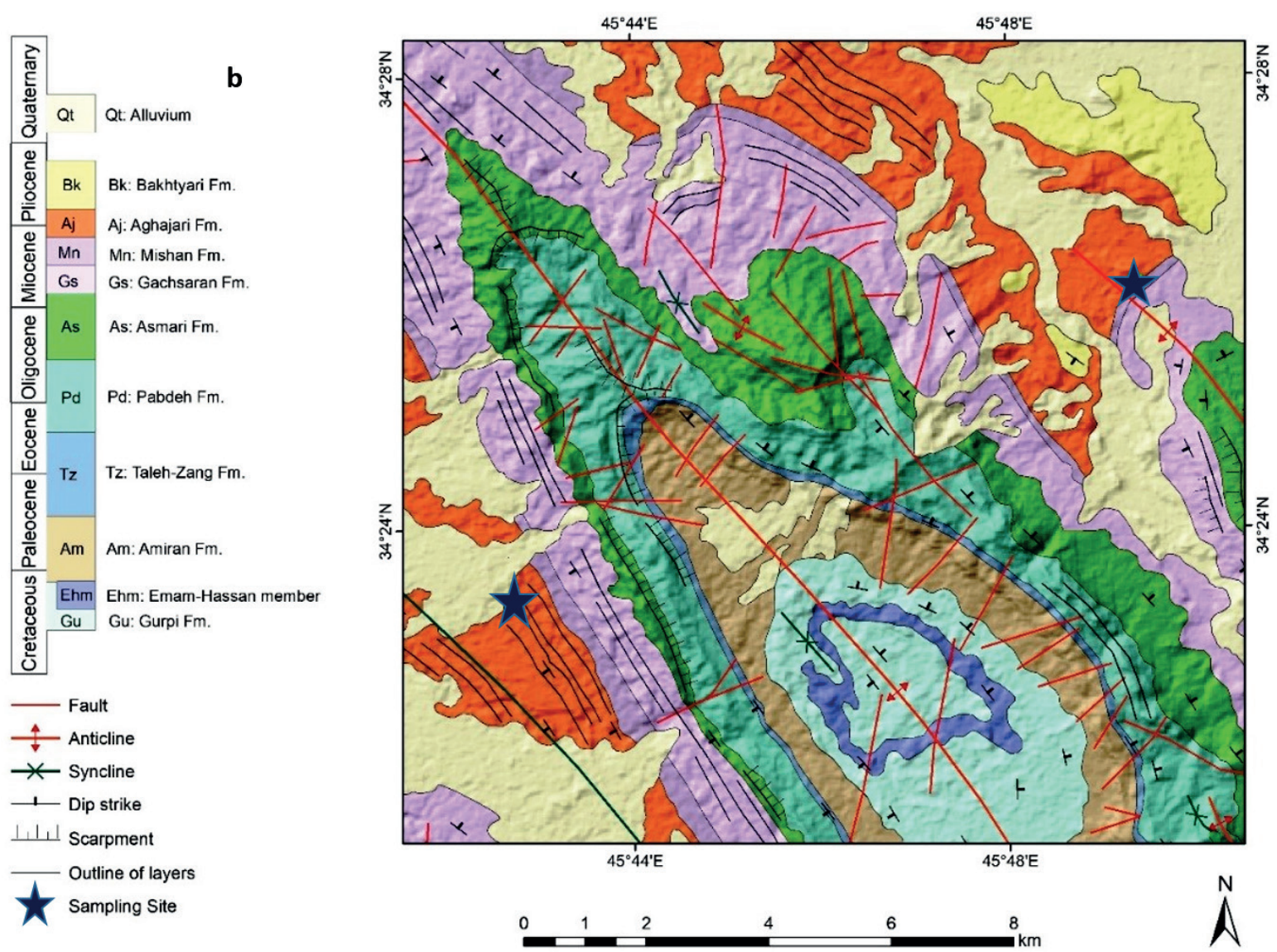

Fig. 1 b) Geological map of the study area and sampling points 


\section{Material and methods}

Rock blocks from calcareous mudstone were selected for studying and preparing laboratory samples from Aghajari Formation. The Aghajari Formation in the study area consists of marl and calcareous mudstones with different colors. Altogether, a large number of rock blocks from 8 rock types were selected based on the physical characteristics of Aghajari Formation and transferred to the Bu-Ali Sina University of Hamedan to provide samples and perform various experiments. The sampling sites consist of the rock blocks including canal and portals of Bazideraz tunnel, which has been drilled for water transport. This water transfer tunnel is drilled perpendicular to the Bazideraz anticline, which is comprised of Gurpey, Asmari, Gachsaran, and Bakhtiari Formations [28].

This anticline is located on the Zagros geological zone. Aghajari Formation in the west of Iran is located within $45^{\circ} 40^{\prime}$ to $45^{\circ} 50^{\prime} \mathrm{E}$ and $34^{\circ} 20^{\prime}$ to $34^{\circ} 30^{\prime} \mathrm{N}$. The geology of the Bazideraz anticline and sampling sites are shown in Fig. 1.

\section{Result and discussions}

To make the dataset needed in this study, mechanical properties of 80 samples including UCS, E, PLT, BPI, and CPI parameters were determined in accordance to the ISRM $[11,13,40]$ and the ASTM [7-9] suggested methods, and Jafari et al. [19], respectively (Fig. 2). The results are listed in Table 1 and basic descriptive statistics for the original dataset are presented in Table 2. As shown in Table 1, each test was performed on 80 samples and the measured values for UCS were between 6.15 and 83.87, for E were between 0.46 and 5.61, for BPI were between 1.75 and 10.15, and for CPI were between 2.18 and 13.36. The minimum and maximum Is $_{(50)}$ values were 0.21 and 5.78, respectively. The reason behind such a wide range is the geological characteristics of the samples, including the amount of lime and fine grain content.

\subsection{Multiple Regression models}

Multiple regression analysis is a powerful modeling technique that can be useful when there exits complex relationships are involved in the problem. Multiple regression analysis can be helpful in rock engineering when more than one variable is effective in rock characteristics. In this research, two approaches of linear and nonlinear multiple regression analyses were used to determine the prediction of UCS and E respectively, using the BPI, CPI, and $\mathrm{Is}_{(50)}$. These indices were analyzed as independent variables while UCS and E were used as dependent variables.

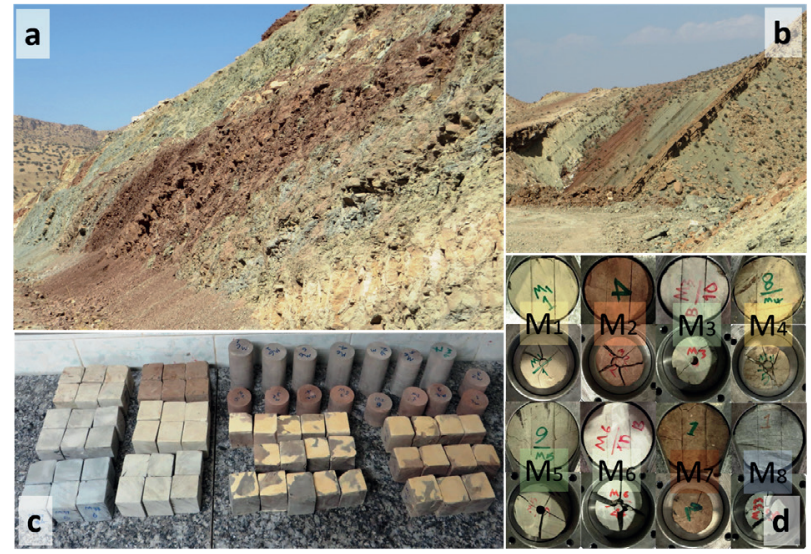

Fig. 2 a) and b) An outcrop of Aghajari Formation from different views and c) and d) the prepared samples for laboratory tests

\subsubsection{Multiple Linear Regression}

The purpose of regression analysis is to determine the relationship between dependent and independent variables. The general form of the linear regression model is as Eq. (1) [37]:

$$
Y=c+b_{1} X_{1}+b_{2} X_{2}+b_{3} X_{3}+\ldots+b_{n} X_{n}
$$

where $Y$ is the dependent variable, $C$ is a constant, $X_{1}$ to $X_{n}$ are independent variables, and $b_{1}$ to $b_{n}$ are partial regression coefficients for $X_{1}$ to $X_{n}$. Finally, two multiple linear regression equations were extracted for predicting UCS and $E$ :

$$
\begin{aligned}
& U C S=-6.479+3.425 * B P I+0.639 * C P I+7.889 * I S_{(50)} \\
& E=0.709+0.205 * B P I-0.066 * C P I+0.579 * I S_{(50)}
\end{aligned}
$$

where $U C S$ is a uniaxial compressive strength (MPa), $E$ is the modulus of elasticity $(\mathrm{GPa}), I_{(50)}$ is the point loading index (MPa), $B P I$ is the block punch index (MPa), and $C P I$ is the cylindrical punch index (MPa).

Fig. 3 presents the accuracy of the predicted UCS and $E$ based on the coefficient of determinations, which are $\mathrm{R}^{2}=0.875$ and $\mathrm{R}^{2}=0.730$, respectively. The difference between the predicted $U C S$ and $E$ (from Eqs. 2-3) and their observed values are presented in Fig. 3.

\subsubsection{Multiple Nonlinear Regression}

In statistics, nonlinear regression is a form of regression analysis in which observational data are modified using a function, which is a nonlinear combination of model parameters and depends on one or more independent variables. These nonlinear relationships are extracted based on the dispersion of $U C S$ and $E$ against independent variables. Therefore, the MNLR method was used to design 
Table 1 Mechanical properties of the used sample data in this study

\begin{tabular}{|c|c|c|c|c|c|c|c|c|c|c|c|}
\hline $\begin{array}{l}\text { Sample } \\
\text { No. }\end{array}$ & $\begin{array}{c}\text { BPI } \\
(\mathrm{MPa})\end{array}$ & $\begin{array}{c}\text { CPI } \\
(\mathrm{MPa})\end{array}$ & $\begin{array}{c}\mathrm{Is}_{(50)} \\
(\mathrm{MPa})\end{array}$ & $\begin{array}{c}\text { UCS } \\
(\mathrm{MPa})\end{array}$ & $\begin{array}{c}E \\
(\mathrm{GPa})\end{array}$ & $\begin{array}{c}\text { Sample } \\
\text { No. }\end{array}$ & $\begin{array}{c}\text { BPI } \\
(\mathrm{MPa})\end{array}$ & $\begin{array}{c}\text { CPI } \\
(\mathrm{MPa})\end{array}$ & $\begin{array}{c}\mathrm{Is}_{(50)} \\
(\mathrm{MPa})\end{array}$ & $\begin{array}{c}\text { UCS } \\
(\mathrm{MPa})\end{array}$ & $\begin{array}{c}\mathrm{E} \\
(\mathrm{GPa})\end{array}$ \\
\hline M1-1 & 2.42 & 2.74 & 0.21 & 9.56 & 0.75 & M5-1 & 5.47 & 3.86 & 0.78 & 27.20 & 1.99 \\
\hline M1-2 & 2.55 & 2.84 & 0.30 & 9.75 & 1.24 & M5-2 & 4.13 & 2.93 & 0.90 & 18.83 & 2.14 \\
\hline M1-3 & 2.58 & 3.18 & 0.34 & 9.83 & 0.96 & M5-3 & 3.79 & 2.25 & 1.05 & 16.51 & 2.33 \\
\hline M1-4 & 2.78 & 3.39 & 0.38 & 9.90 & 1.00 & M5-4 & 3.94 & 2.77 & 1.09 & 18.50 & 2.36 \\
\hline M1-5 & 2.81 & 3.60 & 0.43 & 10.07 & 1.20 & M5-5 & 5.29 & 3.72 & 1.10 & 27.09 & 2.43 \\
\hline M1-6 & 2.97 & 3.66 & 0.46 & 10.29 & 0.84 & M5-6 & 5.83 & 4.36 & 1.18 & 27.80 & 2.45 \\
\hline M1-7 & 3.08 & 3.67 & 0.50 & 14.33 & 2.16 & M5-7 & 3.26 & 2.25 & 1.26 & 15.80 & 2.56 \\
\hline M1-8 & 3.11 & 4.09 & 0.55 & 14.64 & 1.77 & M5-8 & 5.03 & 2.93 & 1.38 & 18.90 & 2.59 \\
\hline M1-9 & 3.24 & 4.16 & 0.76 & 15.07 & 1.89 & M5-9 & 3.24 & 2.18 & 1.43 & 14.35 & 2.66 \\
\hline M1-10 & 3.44 & 4.72 & 0.81 & 16.23 & 1.74 & M5-10 & 6.09 & 4.55 & 1.59 & 29.10 & 2.94 \\
\hline M2-1 & 3.75 & 3.54 & 1.09 & 26.68 & 2.46 & M6-1 & 4.86 & 8.40 & 2.27 & 47.07 & 2.47 \\
\hline M2-2 & 4.00 & 4.24 & 1.21 & 26.98 & 1.98 & M6-2 & 5.14 & 10.23 & 2.52 & 51.17 & 2.80 \\
\hline M2-3 & 4.14 & 5.47 & 1.26 & 27.26 & 1.63 & M6-3 & 8.07 & 11.35 & 2.91 & 52.63 & 2.97 \\
\hline M2-4 & 4.39 & 5.65 & 1.36 & 28.88 & 2.40 & M6-4 & 5.06 & 10.09 & 3.09 & 49.54 & 3.35 \\
\hline M2-5 & 4.44 & 5.89 & 1.47 & 30.49 & 1.63 & M6-5 & 10.15 & 13.36 & 3.98 & 83.87 & 4.04 \\
\hline M2-6 & 5.55 & 6.23 & 1.56 & 30.99 & 2.28 & M6-6 & 8.73 & 11.39 & 4.24 & 54.39 & 4.14 \\
\hline M2-7 & 7.15 & 6.25 & 1.77 & 34.99 & 2.35 & M6-7 & 6.18 & 10.61 & 4.82 & 52.17 & 4.32 \\
\hline M2-8 & 7.24 & 6.66 & 1.79 & 36.79 & 2.73 & M6-8 & 9.13 & 11.91 & 4.95 & 81.66 & 4.40 \\
\hline M2-9 & 7.32 & 7.22 & 2.12 & 37.35 & 2.65 & M6-9 & 9.43 & 12.11 & 5.03 & 82.57 & 5.28 \\
\hline M2-10 & 7.34 & 7.64 & 2.26 & 38.04 & 3.18 & M6-10 & 9.00 & 11.80 & 5.78 & 79.40 & 5.61 \\
\hline M3-1 & 3.60 & 3.87 & 0.93 & 13.40 & 1.07 & M7-1 & 2.34 & 3.57 & 0.39 & 7.39 & 1.32 \\
\hline M3-2 & 2.95 & 3.03 & 1.36 & 11.74 & 1.17 & M7-2 & 2.69 & 3.86 & 0.49 & 12.63 & 1.61 \\
\hline M3-3 & 3.41 & 3.82 & 1.49 & 11.97 & 1.24 & M7-3 & 2.31 & 3.45 & 0.53 & 7.13 & 1.63 \\
\hline M3-4 & 4.52 & 5.88 & 1.57 & 19.49 & 1.26 & M7-4 & 3.00 & 4.12 & 0.54 & 17.61 & 1.64 \\
\hline M3-5 & 3.89 & 4.72 & 1.58 & 14.08 & 1.36 & M7-5 & 2.47 & 3.81 & 0.58 & 11.81 & 1.67 \\
\hline M3-6 & 3.98 & 5.74 & 1.68 & 14.71 & 1.48 & M7-6 & 2.79 & 3.95 & 0.61 & 12.69 & 1.83 \\
\hline M3-7 & 5.17 & 5.93 & 1.70 & 20.66 & 1.52 & M7-7 & 3.61 & 4.61 & 0.66 & 17.63 & 2.03 \\
\hline M3-8 & 5.77 & 6.42 & 1.82 & 21.42 & 1.58 & M7-8 & 3.72 & 4.71 & 0.69 & 17.63 & 2.03 \\
\hline M3-9 & 3.81 & 4.50 & 2.05 & 14.00 & 1.63 & M7-9 & 2.85 & 4.01 & 0.73 & 16.77 & 2.07 \\
\hline M3-10 & 5.20 & 6.26 & 2.13 & 21.08 & 1.72 & M7-10 & 3.83 & 4.83 & 0.85 & 18.51 & 2.37 \\
\hline M4-1 & 1.75 & 2.36 & 0.44 & 6.15 & 0.46 & M8-1 & 3.68 & 6.53 & 0.96 & 12.36 & 1.49 \\
\hline M4-2 & 1.81 & 2.50 & 0.53 & 6.76 & 1.26 & M8-2 & 4.06 & 6.55 & 1.11 & 12.62 & 1.50 \\
\hline M4-3 & 1.91 & 2.68 & 0.57 & 7.56 & 0.94 & M8-3 & 4.52 & 6.84 & 1.17 & 13.42 & 1.57 \\
\hline M4-4 & 2.21 & 3.18 & 0.59 & 8.51 & 1.11 & M8-4 & 4.84 & 6.86 & 1.30 & 14.96 & 2.00 \\
\hline M4-5 & 2.31 & 3.44 & 0.60 & 9.02 & 1.22 & M8-5 & 4.98 & 6.87 & 1.43 & 15.37 & 1.53 \\
\hline M4-6 & 2.57 & 3.63 & 0.62 & 9.44 & 1.18 & M8-6 & 5.04 & 7.01 & 1.60 & 16.17 & 2.07 \\
\hline M4-7 & 2.58 & 3.67 & 0.65 & 14.66 & 0.86 & M8-7 & 5.15 & 7.11 & 1.62 & 24.50 & 4.58 \\
\hline M4-8 & 2.97 & 3.71 & 0.81 & 15.28 & 1.59 & M8-8 & 5.24 & 7.69 & 1.71 & 25.01 & 1.84 \\
\hline M4-9 & 3.28 & 4.01 & 0.88 & 15.54 & 2.53 & M8-9 & 5.74 & 9.45 & 1.76 & 25.10 & 2.89 \\
\hline M4-10 & 3.93 & 5.18 & 0.95 & 15.64 & 1.39 & M8-10 & 5.82 & 10.28 & 2.14 & 25.79 & 2.25 \\
\hline
\end{tabular}


Table 2 Basic descriptive statistics of the parameter

\begin{tabular}{lccccc}
\hline Variable & Observations & Minimum & Maximum & Mean & Std. deviation \\
\hline UCS (MPa) & 80 & 6.147 & 83.872 & 23.536 & 17.755 \\
E (GPa) & 80 & 0.457 & 5.611 & 2.089 & 1.011 \\
BPI (MPa) & 80 & 1.753 & 10.147 & 4.405 & 1.898 \\
CPI (MPa) & 80 & 2.180 & 13.358 & 5.481 & 2.733 \\
Is (50) (MPa) & 80 & 0.214 & 5.784 & 1.448 & 1.152 \\
\hline
\end{tabular}
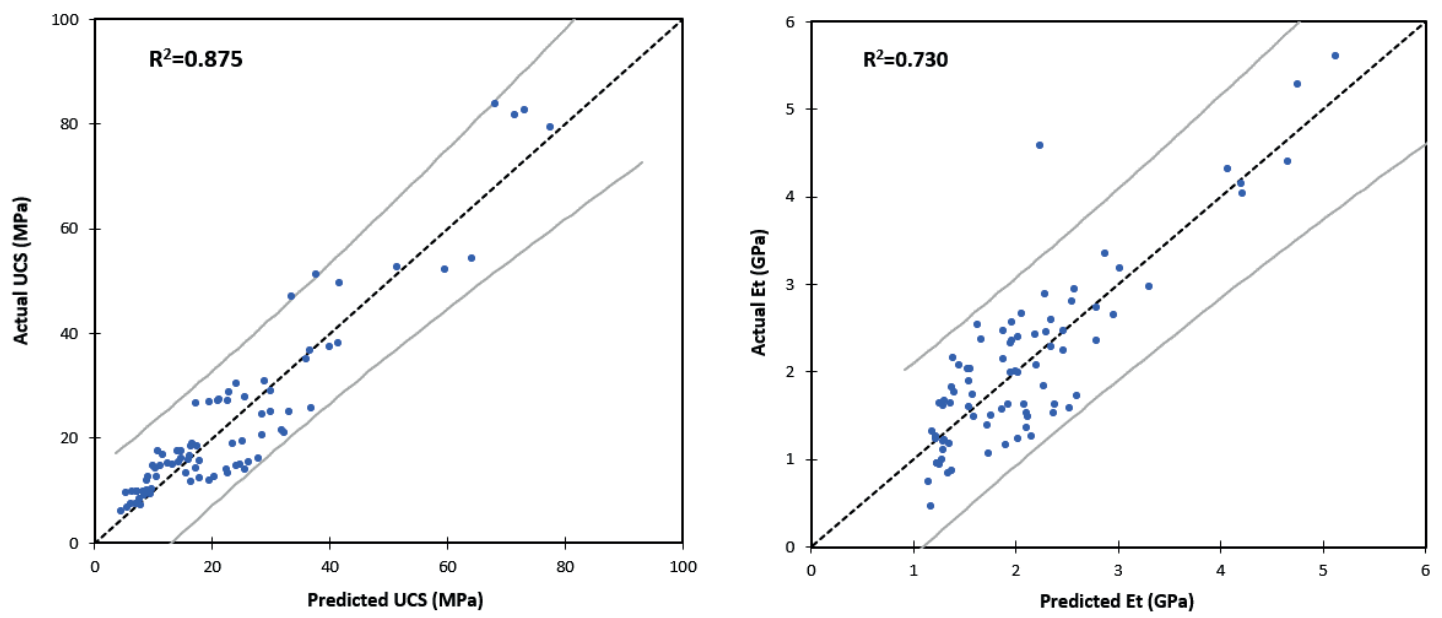

Fig. 3 a) and b) The relationship between actual and predicted UCS and E from MLR analysis (Eqs. 2-3)
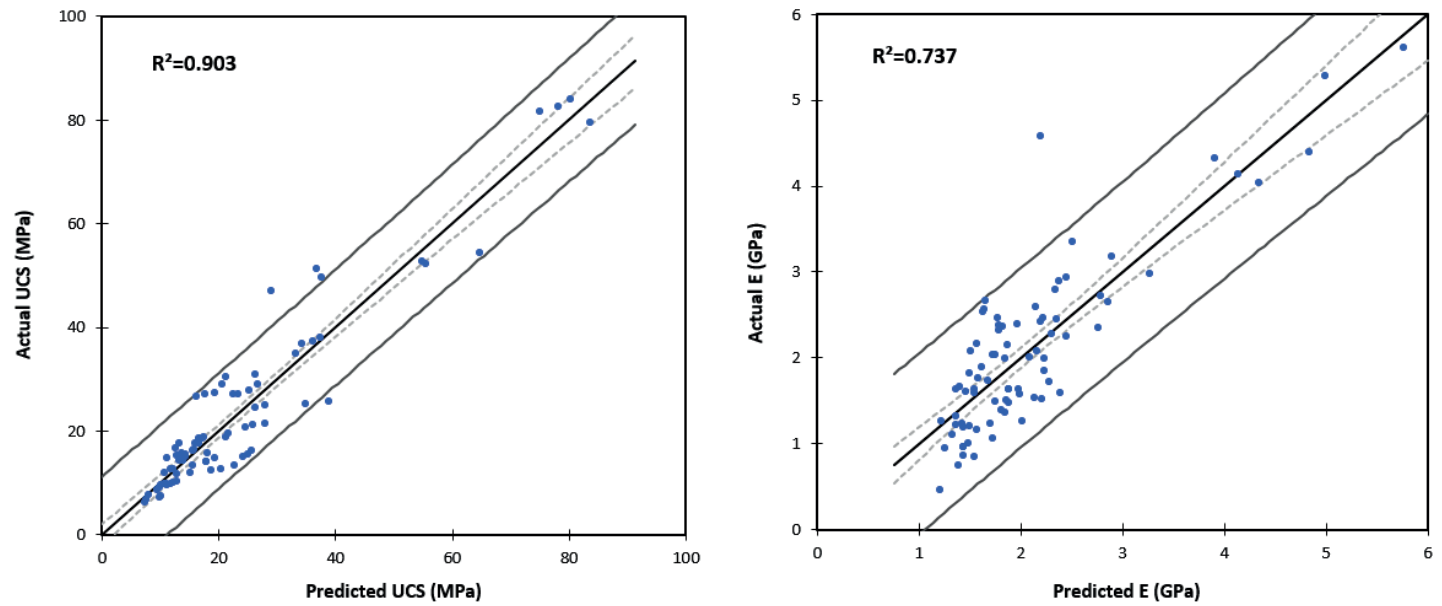

Fig. 4 a) and b) Relationship between actual and predicted $U C S$ and $E$ from MNLR analysis (Eqs. 5-6)

new prediction to UCS and $E$. In order to design the nonlinear multiple regression model, input variables should be similar to inputs of linear multiple statistical model. This model can be written as Eq. (4):

$$
Y=c+b_{1} X_{1}^{c 1}+b_{2} X_{2}^{c 2}+b_{3} X_{3}^{c 3}+\ldots+b_{n} X_{n}^{c 4}
$$

where $Y$ is the predicted values for the response, $C$ is the width from the origin, $X_{1}, X_{2}, X_{3}$, and $X_{n}$ are the predictors, $b_{1}, b_{2}, b_{3}$, and $b_{n}$ are regression coefficients of $X_{1}, X_{2}, X_{3}$, and $X_{n}$, and $c_{1}, c_{2}, c_{3}$, and $c_{n}$ are powers of $X_{1}, X_{2}, X_{3}$, and $X_{n}$, respectively.
Two nonlinear regression models were developed to predict $U C S$ and $E$ (Fig. 4). The equations obtained are shown in Eqs. (5-6):

$$
\begin{aligned}
& U C S=-0.099+4.126 * B P I+0.013 * C P I^{3}+0.134 * I s_{(50)}^{3} \\
& E=0.723+0.275 * B P I-0.0000035^{*} C P I^{3}+0.0133 * I s_{(50)}^{3}
\end{aligned}
$$

The correlation coefficients between the measured and predicted $\left(\mathrm{R}^{2}\right)$ values for $U C S$ and $E$ models are 0.903 and 0.737, respectively. As can be seen, the UCS can be predicted better using the MNLR method rather than $E$. 
Table 3 The structures of the ANN models for the prediction of UCS and $E$

\begin{tabular}{lcccccc}
\hline Model & $\begin{array}{c}\text { Number of input } \\
\text { neuron }\end{array}$ & $\begin{array}{c}\text { Number of hidden } \\
\text { neurons }\end{array}$ & $\begin{array}{c}\text { Number of the output } \\
\text { neuron }\end{array}$ & Network type & Training parameters & Training algorithm \\
\hline UCS & 3 & 7 & 1 & $\begin{array}{c}\text { Feed-forward } \\
\text { backpropagation }\end{array}$ & $\begin{array}{c}\text { Learning rate epochs } \\
26\end{array}$ & $\begin{array}{c}\text { LM (Levenberg- } \\
\text { Marquardt) }\end{array}$ \\
E & 3 & 7 & 1 & Feed-forward & Learning rate epochs & LM (Levenberg- \\
backpropagation & Marquardt) & 10 & \\
\hline
\end{tabular}

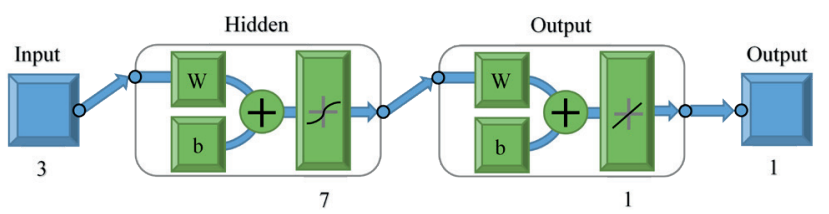

Fig. 5 The structure of the ANN used in this study

\subsection{Neural Network Analysis}

The artificial neural networks (ANNs) are a subset of the artificial intelligence system that has made significant progress in recent years such that it is even used in rock mechanic and engineering geology. The most important feature of the ANNs, which makes them a powerful and preferential tool, is its ability to learn directly from the processing data. An ANN can be defined by three basic components: transfer function, network architecture, and learning rule. Defining these components is the key to solve statistical issues. The simplest and most common form of ANNs used in many engineering sciences is a multilayer perceptron (MLP) network. To MLP used in this study was designed in Matlab Environment. This software provides the ability to design, construct, learn, and evaluate ANNs. The networks used in this study are MLP with Back Propagation (BP) learning law [33]. The architecture of this network is schematically illustrated in Fig. 5. MLPs have three layers of neurons; i.e., input, hidden, and output layers. The input layer is designed to provide data to the network, which receives the data layer from various sources, Therefore, the number of neurons in the input layers depends on the number of resources in the input. In order to estimate $U C S$ and $E$ as dependent variables, independent variables BPI, CPI, and $I S_{(50)}$ were used as network inputs. To find the optimum number of neurons in the hidden layer, we used trial and error method. In each step of the analysis, the number of neurons in the search for the optimal model was increased. Since the weight is a random value, the learning process may be trapped in the local minima. Hence, each developed network was trained several times and then the best model was selected. The learning process stops when the total square error minimizes or falls to an acceptable level. Both ANN models developed for the prediction of $U C S$ and $E$ have a three-layered architecture that includes an input layer (with 3 neurons), a hidden layer (with 7 neurons), and an output layer (1 neuron) (Fig. 5). The parameters of the ANN models are presented in Table 3 . The structures of the ANNs designed in this work are as follows (7-8):

$$
\begin{aligned}
& U C S=f\left(\text { BPI.CPI.IS }_{(50)}\right) \\
& E=f\left(\text { BPI.CPI.IS }_{(50)}\right)
\end{aligned}
$$

Figs. 6 and 7 show the correlation values of the designed ANN for $U C S$ and $E$ prediction in the training, validation, and testing phases and the entire network. As shown in Fig. 6, the UCS values predicted using the ANN have a high correlation with the measured values. However, in Fig. 7, there is a lower correlation between the predicted and the measured values of $E$ compared to the ones reported for UCS index.

\subsection{Adaptive neuro-fuzzy inference (ANFIS)}

ANFIS is a popular hybrid intelligent method that combines ANN and fuzzy logic for producing a reliable predicting system. The method is capable of constructing an input-output network consisting of several nodes through which data are processed by if-then algorithms. Such algorithms are mainly applied to obtain the faults of imprecise models by reviewing the data patterns identified from the previous patterns. As stated by Maiti and Tiwari [30], ANFIS employs the neural training process to adjust the membership function and the associated parameters. In the current study, five layers, each having several nodes having specific functions (Table 4), formed the initial network. The ANFIS model proposed in this study was designed using the Matlab software [31] (Fig. 8). In FIS, three descriptive terms (i.e., soft, moderate, and strong) were assigned to input variables. Grid partition was applied to make the propositions of the fuzzy rules. In the training process, the dataset was randomly used. To determine a selected range of inputs, a minimum and maximum input variable were defined for each variable. A total of 80 datasets were collected and the model was optimized by checking and testing data combined with a hybrid learning algorithm. The results of the ANFIS model tests are presented in Fig. 9. 

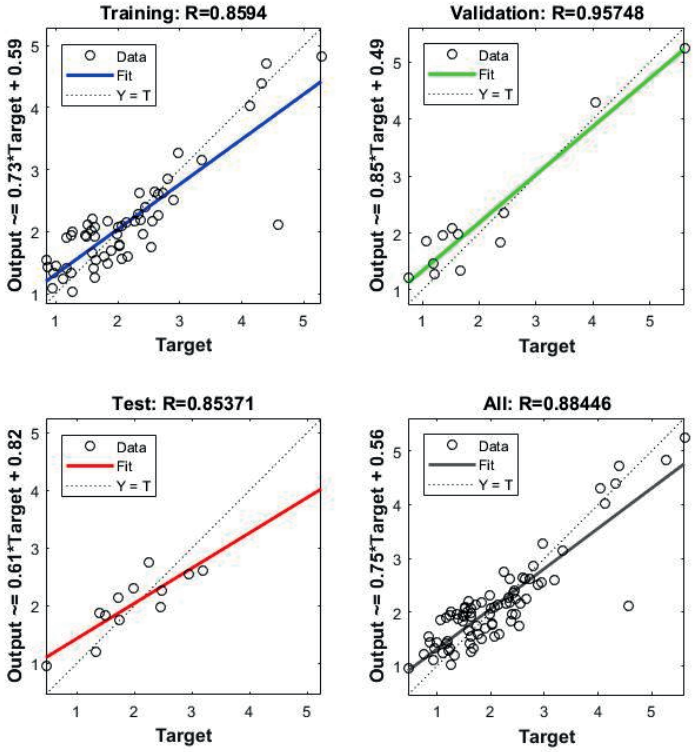

Fig. 6 Regression coefficients for training, validation, testing, and network phases to $U C S$
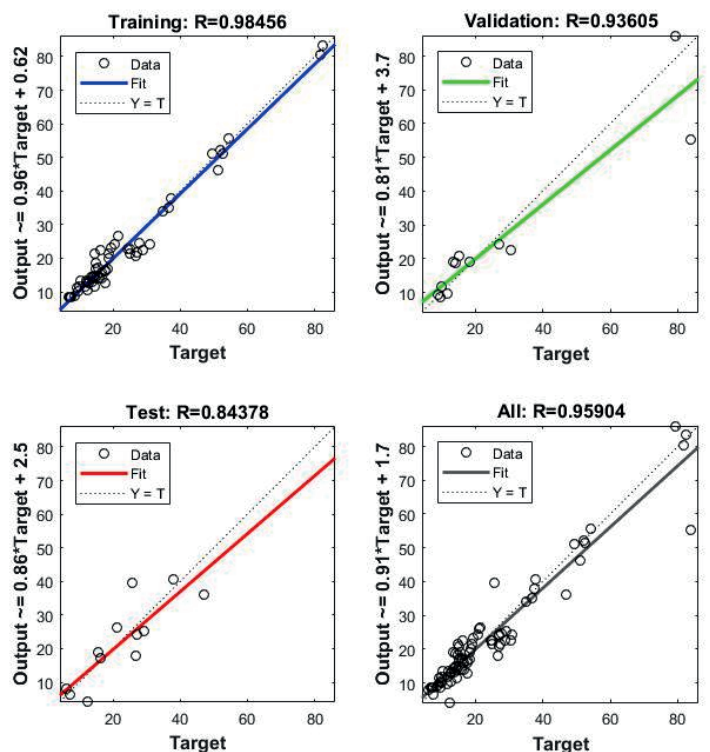

Fig. 7 Regression coefficients for the training, validation, testing, and network phases to $E$

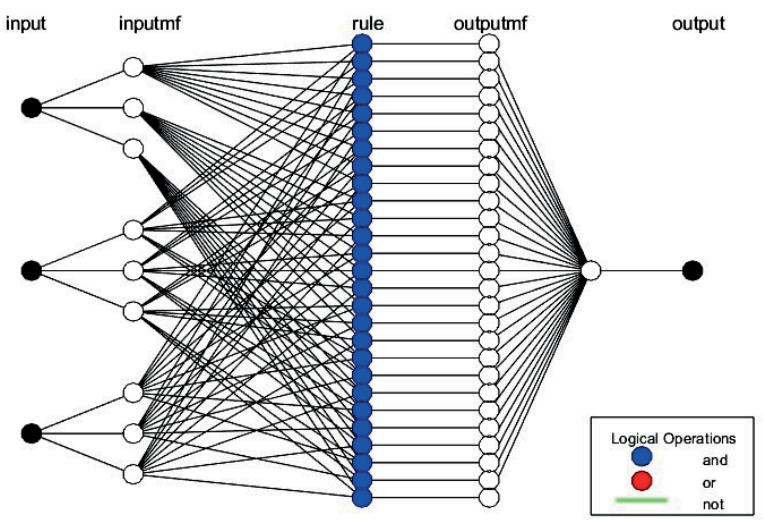

Fig. 8 ANFIS structure employed in the study to predict $U C S$ and $E$
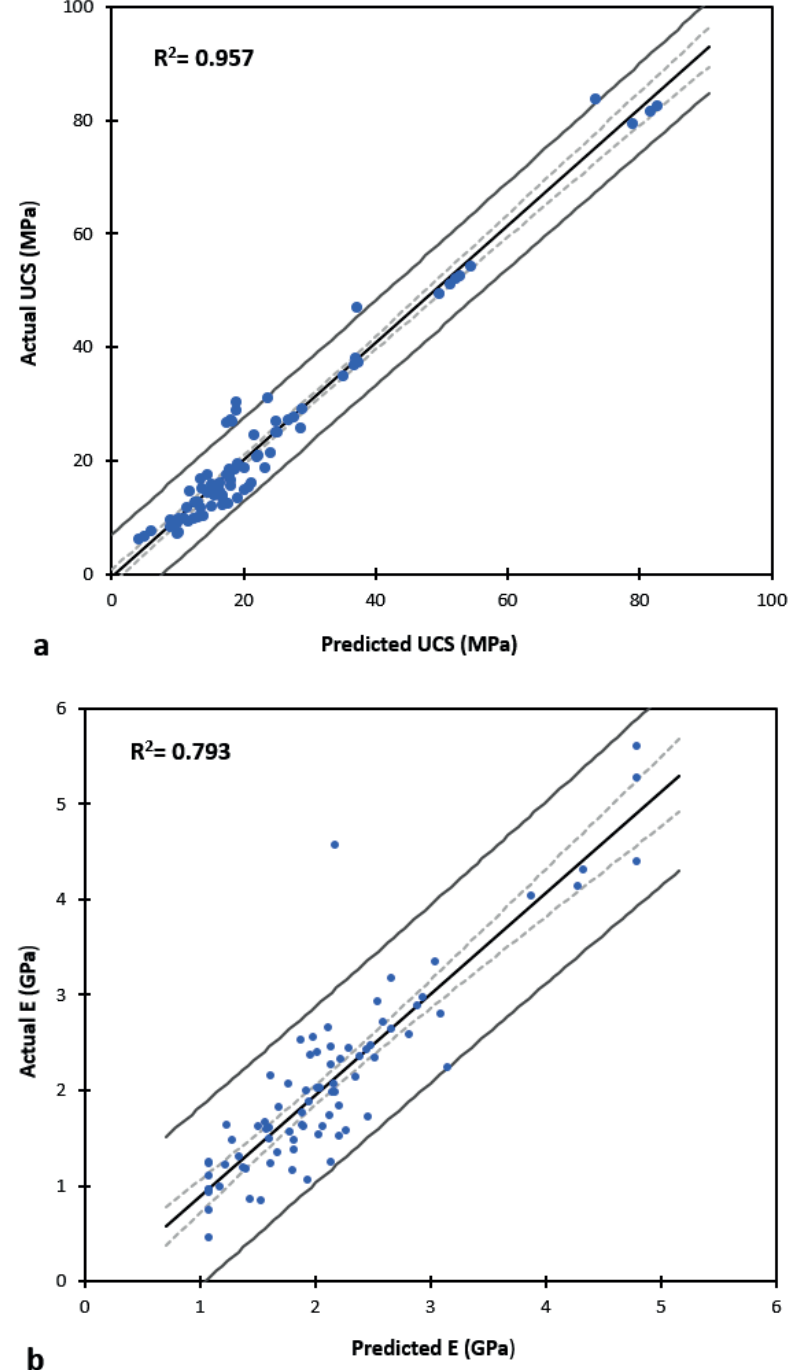

Fig. 9 Relation between predicted and measured for a) $U C S(\mathrm{MPa})$ and b) $E(\mathrm{GPa})$ by ANFIS model

Table 4 Different parameter and their corresponding values used for

\begin{tabular}{lcc} 
& ANFIS & \\
\hline ANFIS parameter type & Value of UCS & Value of E \\
\hline MF type & Triangular & Trapezoidal \\
Number of MFs & 3 & 3 \\
Output function & Constant & Constant \\
Number of fuzzy rules & 27 & 27 \\
Number of training data & 56 & 56 \\
Number of checking data & 12 & 12 \\
Number of testing data & 12 & 12 \\
\hline
\end{tabular}

\subsection{Performances analysis of models}

In this research, the performances of models designed by ANN, linear multiple regression, and nonlinear multiple regression were assessed using determination coefficients $\left(\mathrm{R}^{2}\right)$, mean absolute percentage error $(M A P E)$, and variance account for $(V A F)$ (Eqs. 9-10). 
$M A P E=\frac{100}{N} \times \sum_{i=1}^{N}\left[\frac{x_{i}-x_{i}^{\prime}}{x_{i}}\right]$

$V A F_{i}=\left[1-\frac{\operatorname{var}\left(x_{i}-x_{i}^{\prime}\right)}{\operatorname{var}\left(x_{i}\right)}\right] \times 100$

where $N$ is the total number of the measured data point and $x_{i}$ and $x_{i}^{\prime}$ are the measured and predicted values, respectively [6-15]. The model will be excellent when MAPE has the smallest value and $V A F$ is $100 \%$. The obtained values of $V A F$ and MAPE and the comparison of VAF, MAPE, and $\mathrm{R}^{2}$ for predicting $U C S$ and $E$ are shown in Table 4.

As shown in Table 5, ANFIS model provided the most accurate values in predicting the desired values $(M A P E=$ $13.89 \%, V A F=95.6 \%$, and $\mathrm{R}^{2}=0.957$ in predicting $U C S$ and $M A P E=17.96 \%, V A F=79.10 \%$, and $\mathrm{R}^{2}=0.793$ in predicting $E$ ). Moreover, the ANN model (MAPE $=15.81 \%$, $V A F=91.27 \%$, and $\mathrm{R} 2=0.920$ in predicting UCS and $M A P E=20.45 \%, V A F=78.25 \%$, and $\mathrm{R}^{2}=0.782$ in predicting $E$ ) represents the second best results for the prediction of the $U C S$ and $E$ values compared to other statistical models applied in this study. Finally, MNLR (MAPE $=$ $19.45 \%, V A F=90.34 \%$, and $\mathrm{R}^{2}=0.903$ in predicting $U C S$ and $M A P E=24.18 \%, V A F=73.73 \%$, and $\mathrm{R}^{2}=0.737$ in

Table 5 The obtained values of $V A F$ and MAPE for the MLR, MNLR, ANN and ANFIS models

\begin{tabular}{lcccccc}
\hline $\begin{array}{l}\text { Analysis } \\
\text { method }\end{array}$ & \multicolumn{3}{c}{ UCS (MPa) } & \multicolumn{3}{c}{ E (GPa) } \\
\hline & $\begin{array}{c}\text { MAPE } \\
(\%)\end{array}$ & $\begin{array}{c}\text { VAF } \\
(\%)\end{array}$ & R2 & MAPE & VAF & R2 \\
& 24.72 & 85.76 & 0.875 & 24.08 & 63.10 & 0.730 \\
MLR & 19.45 & 90.34 & 0.903 & 24.18 & 73.73 & 0.737 \\
MNLR & 15.81 & 91.27 & 0.920 & 20.45 & 78.25 & 0.782 \\
ANN & 13.89 & 95.60 & 0.957 & 17.96 & 79.10 & 0.793 \\
ANFIS & & & & & &
\end{tabular}

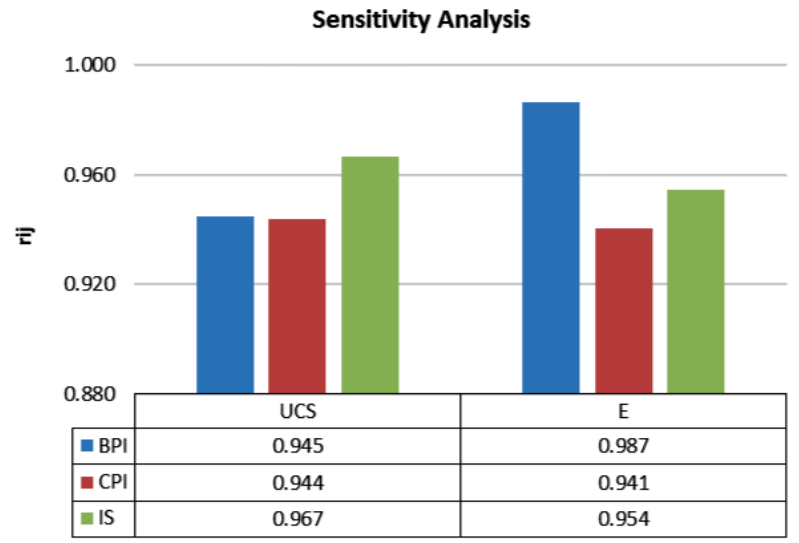

Fig. 10 Strengths of relation between input and output parameters to $U C S$ and $E$ predicting E) and MLR (MAPE $=24.72 \%, V A F=85.76 \%$, and $\mathrm{R}^{2}=0.875$ in predicting $U C S$ and $M A P E=24.08 \%$, $V A F=63.10 \%$, and $\mathrm{R}^{2}=0.730$ in predicting $E$ ) models have ranked as the third and fourth best models respectively for predicting the UCS and $E$ values in this study.

\section{Sensitivity analysis}

Relative impact for parameters of network system was predicted using the sensitivity analysis in cosine amplitude method [43]. For this purpose, data array $\mathrm{X}$ was built according to the data pairs in the following pattern:

$X=\left\{x_{1}, x_{2}, x_{3}, \ldots, x_{n}\right\}$

where $\mathrm{xi}$ in the array $\mathrm{X}$ is the length vector of $\mathrm{m}$ as:

$x_{i}=\left\{x_{i 1}, x_{i 2}, x_{i 3}, \ldots, x_{i m}\right\}$

Eq. (13) presents the strength of the relation (rij) between the data sets $\mathrm{Xi}$ and $\mathrm{Xj}$.

$r_{i j}=\frac{\sum_{k=1}^{m} x_{i k} x_{j k}}{\sqrt{\sum_{k=1}^{m} x^{2} i k \sum_{k=1}^{m} x^{2} i k}}$

Fig. 10 shows the strengths of the relations $\left(r_{i j}\right.$ values) between the input and output (UCS and E) variables. The results indicate that among the three independent variables, $I s_{(50)}$ has the greatest impact on UCS with BPI CPI being in the next rankings. The BPI has the highest impact on the E, $I s_{(50)}$, and CPI in the order of their appearance.

\section{Conclusions}

In this paper, ANFIS, ANN, and multiple statistics were used to predict the UCS and E parameters of Aghajari calcareous mudstones. According to the results of linear and nonlinear regression analyses, a strong statistical relationship was found between UCS and the mechanical properties. The $\mathrm{R}^{2}$ value for MLR, MNLR, ANN, and ANFIS models to predict UCS indicate a more accurate performance compared to $\mathrm{E}$ models, due to the strong relationship between BPI, CPI, and $I S_{(50)}$ compared to E. In addition to validating the statistical models, when the $\mathrm{R}^{2}$ values are close to each other, VAF and MAPE are effective in the performance assessment of a variety of models. Comparing the observed and estimated measures based on the goodness of fit statistics demonstrated that the ANFIS models outperform the statistical models in predicting actual $U C S$ and $\mathrm{E}$ values. Furthermore, the MAPE and $V A F$ values for the ANFIS models were found to be higher than the multiple regression models. For the ANFIS 
model, $V A F$ and MAPE were calculated 95.6 and 13.89 for $U C S$, and 79.1 and 17.96 for $E$, respectively. It was concluded that the ANFIS results indicate very close agreement for the UCS and $E$ with the laboratory datasets as compared with the multiple regression models predictions. Four equations were proposed based on the multiple linear, nonlinear regressions, ANN, and ANFIS analyses for predicting $U C S$ and $E$ of the calcareous mudstones. However, it has to be noted that the predicted equations derived by the authors are valid only for the studied calcareous mudstones or soft rocks with similar characteristics. So, additional studies are needed to verify these relationships.

\section{Acknowledgments}

The authors would like to thank the Faculty of Sciences of Bu-Ali Sina University for the financial support. Also, a collaboration of Kermanshah Province Gas Company is gratefully acknowledged.

\section{References}

[1] Abatan, A. O., Akinyemi, O. D., Olowofela, J. A., Ajiboye, G. A., Salako, F. K. "Experimental investigation of factors affecting compressional and shear wave velocities in shale and limestone of Ewekoro formation of Southern Nigeria sedimentary basin", Environmental Earth Sciences, 75(1442), 2016. https://doi.org/10.1007/s12665-016-6229-6

[2] Armaghani, D. J., Mohamad, E. T., Momeni, E., Monjezi, M., Narayanasamy, M. S. "Prediction of the strength and elasticity modulus of granite through an expert artificial neural network", Arabian Journal of Geosciences, 9(48), 2016. https://doi.org/10.1007/s12517-015-2057-3

[3] Aksoy, C. O. "Performance prediction of impact hammers by block punch index for weak rock masses", International Journal of Rock Mechanics and Mining Science, 46(8), pp. 1383-1388, 2009. https://doi.org/10.1016/j.ijrmms.2009.02.008

[4] Aksoy, C. O., Kantarci, O., Ozacar, V. "An example for estimation of rock mass deformations around an underground opening by numerical modeling", International Journal of Rock Mechanics and Mining Science, 47(2), pp. 272-278, 2010.

https://doi.org/10.1016/j.jirmms.2009.12.001

[5] Aksoy, C. O., Ozacar, V., Demirel, N., Ozer, S. C., Safak, S. "Determination of instantaneous breaking rate by geological strength index, block punch index and power of impact hammer for various rock mass conditions", Tunnelling and Underground Space Technology, 26(4), pp. 534-540, 2011. https://doi.org/10.1016/j.tust.2011.02.005

[6] Grima, M. A., Babuška, R. "Fuzzy model for the prediction\& of unconfined compressive strength of rock samples", International Journal of Rock Mechanics and Mining Sciences, 36(3), pp 339349, 1999.

https://doi.org/10.1016/S0148-9062(99)00007-8
[7] ASTM, "D5731-16 Standard Test Method for Determination of the Point Load Strength Index of Rock and Application to Rock Strength Classifications", ASTM International, West Conshohocken, Pennsylvania, United States, 2016.

https://doi.org/10.1520/D5731-16

[8] ASTM, "D2938-95 Standard Test Method for Unconfined Compressive Strength of Intact Rock Core Specimens", (Reapproved 2002), ASTM International, West Conshohocken, Pennsylvania, United States, 1995. https://doi.org/10.1520/D2938-95R02

[9] ASTM, "E111-97 Standard Test Method for Young's Modulus, Tangent Modulus, and Chord Modulus", ASTM International, West Conshohocken, Pennsylvania, United States, 1997.

https://doi.org/10.1520/E0111-97

[10] Basu, A., Kamran, M., "Point load test on schistose rocks and its applicability in predicting uniaxial compressive strength", International Journal of Rock Mechanics and Mining Science, 47(5), 823-828, 2010. https://doi.org/10.1016/j.ijrmms.2010.04.006

[11] Bieniawski, Z. T., Bernede, M. J. "Suggested methods for determining the uniaxial compressive strength and deformability of rock materials", International Journal of Rock Mechanics and Mining Science and Geomechanics Abstracts, 16(2), pp. 138-140, 1979. https://doi.org/10.1016/0148-9062(79)91451-7

[12] Diamantis, K., Gartzos, E., Migiros, G. "Study on uniaxial compressive strength, point load strength index, dynamic and physical properties of serpentinites from Central Greece: test results and empirical relations", Engineering Geology, 108(3-4), pp. 199-207, 2009. https://doi.org/10.1016/j.enggeo.2009.07.002

[13] Franklin, J. A. "Suggested method for determining point load strength", International Journal of Rock Mechanics and Mining Science and Geomechanics Abstracts, 22(2), pp. 51-60, 1985. https://doi.org/10.1016/0148-9062(85)92327-7

[14] Gokceoglu, C., Aksoy, H. "New approaches to the characterization of clay-bearing, densely jointed and weak rock masses", Engineering Geology, 58(1), pp. 1-23, 2000. https://doi.org/10.1016/S0013-7952(00)00032-6

[15] Gokceoglu, C., Zorlu, K. "A fuzzy model to predict the uniaxial compressive strength and the modulus of elasticity of a problematic rock", Engineering Applications of Artificial Intelligence, 17(1), pp. 61-72, 2004.

https://doi.org/10.1016/j.engappai.2003.11.006

[16] Heidari, M., Khanlari, G. R., Momeni, A. A. "Prediction of Elastic Modulus of Intact Rocks Using Artificial Neural Networks and nonLinear Regression Methods", Australian Journal of Basic and Applied Sciences, 4(12), pp. 5869-5879, 2010. Available at http:// www.ajbasweb.com/old/ajbas/2010/5869-5879 [Accessed: 14.11.2018]

[17] Heidari, M., Khanlari, G. R., Momeni, A. A. "Prediction of Elastic Modulus of Intact Rocks Using Artificial Neural Networks and non-Linear Regression Methods", Australian Journal of Basic and Applied Sciences, 4(12), pp. 5869-5879, 2010. Available at http:// www.ajbasweb.com/old/ajbas/2010/5869-5879 [Accessed: 14.11.2018]

[18] Heidari, M., Khanlari, G. R., Torabi-Kaveh, M., Kargarian, S. "Predicting the uniaxial compressive and tensile strengths of gypsum rock by point load testing". Rock Mechanics and Rock Engineering, 45(2), pp. 265-273, 2012.

https://doi.org/10.1007/s00603-011-0196-8 
[19] Jafari, E., Nikudel, M. R., Ahmadi, M. "Evaluation of Strength properties of rocks using results of cylinder punch and block punch tests", Journal of Science, University of Tehran, 36(1), pp. 169-183, 2010.

[20] Jalali, S. H., Heidari, M., Mohseni, H. "Comparison of models for estimating uniaxial compressive strength of some sedimentary rocks from Qom Formation", Environmental Earth Sciences, 76, 753, 2017. https://doi.org/10.1007/s12665-017-7090-y

[21] Kahraman, S., Gunaydin, O., Alber, M., Fener, M. "Evaluating the strength and deformability properties of Misis fault breccia using artificial neural networks", Expert Systems with Applications, 36(3), pp. 6874-6878, 2009. https://doi.org/10.1016/j.eswa.2008.08.002

[22] Karakul, H., Ulusay, R., Isik, N. S. "Empirical models and numerical analysis for assessing strength anisotropy based on block punch index and uniaxial compression tests", International Journal of Rock Mechanics and Mining Science, 47(4), pp. 657-665, 2010. https://doi.org/10.1016/j.ijrmms.2010.03.006

[23] Kohno, M., Maeda, H. "Relationship between point load strength index and uniaxial compressive strength of hydrothermally altered soft rocks", International Journal of Rock Mechanics and Mining Science, 50, pp. 147-157, 2012. https://doi.org/10.1016/j.ijrmms.2012.01.011

[24] Khanlari, G.-R., Heidari, M., Sepahi-Gero, A.-A., Fereidooni, D. "Qualification of strength anisotropy of metamorphic rocks of the Hamedan province, Iran, as determined from cylindrical punch, point load and Brazilian tests", Journal of Engineering Geology, 169, pp. 80-90, 2014. https://doi.org/10.1016/j.enggeo.2013.11.014

[25] Khanlari, G-R., Rafiei, B., Abdi-lor, Y. "An experimental investigation of the Brazilian tensile strength and failure patterns of laminated sandstones", Journal of Rock Mechanics and Rock Engineering, 48(2), pp. 843-852, 2015. https://doi.org/10.1007/s00603-014-0576-y

[26] Khanlari, G. R., Abdi-lor, Y. "Upper Red Formation sandstones under Brazilian and point load test conditions", Iranian Journal of Engineering Geology, 7 (3-4), pp. 103-110, 2016.

[27] Naseri, F., Khanlari, G. H. "The prediction of compressive strength of travertines with special reference to laminae-orientation using index tests", Journal of Geopersia, 7(2), pp. 279-299, 2017. https://doi.org/10.22059/geope.2017.226625.648296

[28] Khosro Tehrani, K. "Geology of Iran", Kaleidar Publication, Tehran, Iran, 2005.

[29] Manouchehrian, A., Sharifzadeh, M., Hamidzadeh-Moghadam, R. "Application of artificial neural networks and multiple statistics to estimate UCS using textural characteristics", International Journal of Mining Science and Technology, 22(2). pp. 229-236, 2012. https://doi.org/10.1016/j.ijmst.2011.08.013

[30] Maiti, S., Tiwari, R. K. "A comparative study of artificial neural networks, Bayesian neural networks and adaptive neuro-fuzzy inference system in groundwater level prediction", Environmental Earth Sciences, 71(7), pp. 3147-3160, 2014. https://doi.org/10.1007/s12665-013-2702-7

[31] Matlab R2017a. "Software for technical computing and model-based design", The Math Works Inc. 2017
[32] Mishra, D. A., Basu, A. "Use of the block punch test to predict the compressive and tensile strengths of rocks", International Journal of Rock Mechanics and Mining Science, 51, pp. 119-127, 2012. https://doi.org/10.1016/j.ijrmms.2012.01.016

[33] Rogers, S. J., Chen, H. C., Kopaska-Merkel, D. C., Fang, J. H. "Predicting permeability from porosity using artificial neural networks", AAPG, 79(12), pp. 1786-1796, 1995.

[34] Sonmez, H., Gokceoglu, C., Nefeslioglu, H. A., Kayabasi, A. "Estimation of rock modulus: for intact rocks with an artificial neural network and for rock masses with a new empirical equation", International Journal of Rock Mechanics and Mining Science, 43(2), pp. 224-235, 2006. https://doi.org/10.1016/j.ijrmms.2005.06.007

[35] Sonmez, H., Tuncay, E., Gokceoglu, C. "Models to predict the uniaxial compressive strength and the modulus of elasticity for Ankara Agglomerate", International Journal of Rock Mechanics and Mining Science, 41(5), pp. 717-729, 2004. https://doi.org/10.1016/j.ijrmms.2004.01.011

[36] Sonmez, H., Tunusluoglu, C. "New considerations on the use of block punch index for predicting the uniaxial compressive strength of rock material", International Journal of Rock Mechanics and Mining Science, 45(6), pp. 1007-1014, 2008. https://doi.org/10.1016/j.ijrmms.2007.11.001

[37] Tiryaki, B. "Predicting intact rock strength for mechanical excavation using multiple statistics, artificial neural networks and regression trees", Engineering Geology, 99(1-2), pp. 51-60, 2008.

https://doi.org/10.1016/j.enggeo.2008.02.003

[38] Torabi-Kaveh, M., Naseri, F., Saneie, S., Sarshari, B. "Application of artificial neural networks and multiple statistics to predict UCS and E using physical properties of Asmari limestones", Arabian journal of Geosciences, 8(5), pp. 2889-2897, 2014. https://doi.org/10.1007/s12517-014-1331-0

[39] Ulusay, R., Gokceoglu, C. "The modified block punch index test", Canadian Geotechnical Journal, 34(6), pp. 991-1001, 1997. https://doi.org/10.1139/t97-049

[40] Ulusay, R., Gokceoglu, C., Sulukcu, S. "Draft ISRM suggested method for determining block punch strength index (BPI)", International Journal of Rock Mechanics and Mining Science, 38(8), pp. 1113-1119, 2001. https://doi.org/10.1016/S1365-1609(01)00078-8

[41] van der Schrier, J. S. "The block punch index test", Bulletin of the International Association of Engineering Geology, 38(1), pp. 121-126, 1988. https://doi.org/10.1007/BF02590455

[42] Li, D., Wong, L. N. Y. "Point load test on meta-sedimentary rocks and correlation to UCS and BTS", Rock Mechanics and Rock Engineering, 46(4), pp. 889-896, 2012. https://doi.org/10.1007/s00603-012-0299-x

[43] Yang, Y., Zang, O. "A hierarchical analysis for rock engineering using artificial neural networks", Rock Mechanics and Rock Engineering, 30(4), pp. 207-222, 1997. https://doi.org/10.1007/BF01045717 
[44] Yilmaz, I., Yuksek, G. "Prediction of the strength and elastic modulus of gypsum using multiple regression, ANN, and ANFIS models", International Journal of Rock Mechanics and Mining Science, 46(4), pp. 803-810, 2009.

https://doi.org/10.1016/j.ijrmms.2008.09.002
[45] Zorlu, K., Gokceoglu, C., Ocakoglu, F., Nefeslioglu, H. A. Acikalin S. "Prediction of uniaxial compressive strength of sandstones using petrography-based models", Engineering Geology, 96, pp. 141-158, 2008.

https://doi.org/10.1016/j.enggeo.2007.10.009 